\title{
Influence of the Incorporation of Transition Metals on the Basicity of Mg,Al-Mixed Oxides and on Their Catalytic Properties for Transesterification of Vegetable Oils
}

\author{
Paula M. Veiga, ${ }^{1}$ Zilacleide S. B. Sousa, ${ }^{1}$ Carla M. S. Polato, ${ }^{2}$ Marcio F. Portilho, ${ }^{3}$ \\ Cláudia O. Veloso, ${ }^{1}$ and Cristiane A. Henriques ${ }^{1}$ \\ ${ }^{1}$ UERJ, Instituto de Química, Programa de Pós-graduação em Engenharia Química, Rua São Francisco Xavier, 524, Maracanã, 20550- \\ 900 Rio de Janeiro, RJ, Brazil \\ ${ }^{2}$ INPI, Rua Mayrink Veiga, 9, Centro, 20090-910 Rio de Janeiro, RJ, Brazil \\ ${ }^{3}$ CENPES/PETROBRAS, PDAB/CB, Avenida Horacio Macedo, 950, Cidade Universitária, 21941-915 Rio de Janeiro, RJ, Brazil
}

Correspondence should be addressed to Cristiane A. Henriques; cristihenriques@terra.com.br

Received 27 December 2012; Revised 11 March 2013; Accepted 14 March 2013

Academic Editor: Mohammed M. Bettahar

Copyright (C) 2013 Paula M. Veiga et al. This is an open access article distributed under the Creative Commons Attribution License, which permits unrestricted use, distribution, and reproduction in any medium, provided the original work is properly cited.

\begin{abstract}
The transesterification of vegetable oils produces fatty acid methyl esters (biodiesel). Biodiesel is a nonpolluting alternative fuel produced from renewable resources whose chemical and physical properties closely resemble those of the petroleum diesel fuel and does not contribute to the greenhouse effect. The use of solid catalysts makes biodiesel production processes environmentally friendly. In this work, $\mathrm{Mg}$, Al-mixed oxides derived from $\mathrm{Mg}$, Al-hydrotalcite-like compound with an $\mathrm{M}^{3+} /\left(\mathrm{M}^{2+}+\mathrm{M}^{3+}\right) \mathrm{molar}$ ratio of 0.25 , in which $\mathrm{Mg}$ or $\mathrm{Al}$ was partially replaced by $\mathrm{Co}^{2+}, \mathrm{Cu}^{2+}, \mathrm{Cr}^{3+}$, or $\mathrm{Fe}^{3+}$, were prepared, characterized, and evaluated as catalysts for the transesterification of soybean oil with methanol. The results have indicated that the incorporation of transition metal influenced both textural and base properties. All the evaluated catalysts were active for the studied reaction. The catalytic activity followed the order $\mathrm{Cr}-\mathrm{MO}<\mathrm{Co}-\mathrm{MO}<\mathrm{Cu}-\mathrm{MO}<\mathrm{Fe}-\mathrm{MO}<\mathrm{MO}$ and could be explained by mesoporous volume.
\end{abstract}

\section{Introduction}

Hydrotalcite-like compounds (HTLCs) are layered double hydroxides (LDHs) that have been investigated during the last two decades as adsorbents, anion exchangers, and catalysts or catalyst precursors for different types of chemical reactions. The general formula of the HTLCs is

$$
\left(\mathrm{M}_{1-x}^{2+} \mathrm{M}_{x}^{3+}(\mathrm{OH})_{2}\right)^{x+}\left(\mathrm{A}_{x / m}^{m-}\right) \cdot n \mathrm{H}_{2} \mathrm{O}
$$

where the divalent ion can be $\mathrm{Mg}^{2+}, \mathrm{Ca}^{2+}, \mathrm{Zn}^{2+}, \mathrm{Cu}^{2+}, \mathrm{Co}^{2+}$, or $\mathrm{Ni}^{2+}$, the trivalent ion can be $\mathrm{Al}^{3+}, \mathrm{Fe}^{3+}$, or $\mathrm{Cr}^{3+}$, the compensation anion can be $\mathrm{OH}^{-}, \mathrm{Cl}^{-}, \mathrm{NO}_{3}{ }^{-}, \mathrm{CO}_{3}{ }^{2-}$, or $\mathrm{SO}_{4}{ }^{2-}$, and $x$ can take values between 0.17 and 0.33 [1].

$\mathrm{Mg}, \mathrm{Al}$-hydrotalcite is the most common $\mathrm{LDH}$, and it can also be synthesized in a ternary form in which $\mathrm{Mg}$ or $\mathrm{Al}$ is partially replaced by a transition metal cation. Thermally treating HTLCs induces dehydration, dehydroxylation, and loss of compensation anions, forming mixed oxides/hydroxides with basic properties and a poorly crystallized structure [2]. These oxides present small particle size, large specific surface area, and basic properties attributed to hydroxyl groups, different $\mathrm{O}^{2-}-\mathrm{M}^{2+}$ acid-base pairs, and $\mathrm{O}^{2-}$ anions [3-6]. The acid-base properties and, as a consequence, the catalytic activity and selectivity of these $\mathrm{Mg}, \mathrm{Me}, \mathrm{Al}-$ mixed oxides depend on chemical composition (type of $\mathrm{Me}$ cation and $\mathrm{Mg} / \mathrm{Me} / \mathrm{Al}$ molar ratio) and on the conditions of the thermal treatment used to decompose the hydrotalcite precursor. So, they can be tailored to the process under study aiming at increasing their activity and/or selectivity. Their main applications as basic catalyst include aldol, nitroaldol, Knoevenagel, and Claisen-Schmidt condensations, alkylation 
of ketones and phenols, Michael additions, glycerolysis of fats for the manufacture of monoglycerides, selective reduction of unsaturated ketones/aldehydes by hydrogen transfer from alcohols, and more recently transesterification of vegetable oils for biodiesel production [2, 4-10].

Biodiesel is a nontoxic, biodegradable, and renewable fuel which use has a beneficial impact on the environment. When compared to conventional fossil diesel, it offers many advantages such as high cetane number, high lubricity, high flash point, low viscosity, and lower emissions of $\mathrm{CO}, \mathrm{SO}_{2}$, unburned hydrocarbons, polyaromatic hydrocarbons, and particulate matter [11].

The conventional process of biodiesel production is the transesterification of vegetable oils with a short carbon-chain alcohol (methanol or ethanol) in the presence of homogeneous basic catalysts. However, these catalytic systems have some technological problems, such as removal of basic catalysts after reaction, production of a large amount of wastewater, and emulsification. Besides, the growing concern about the environment is leading the chemical industry to develop less pollutant and more selective chemical processes. So, solid basic catalysts have received increasing attention as a substitute for the highly pollutant liquid homogeneous catalysts in organic reactions because they reduce or eliminate the problems cited previously, and can be reused and adapted to continuous processes in fixed bed reactors.

In this context, several studies related to the use of basic solids such as oxides or hydroxides of alkali metals supported on silica or alumina $[12,13]$, mixed oxides derived from hydrotalcite $[9,10,14-18]$, and other oxides [19-21] as catalysts for biodiesel production are found in the literature. Concerning the mixed oxides derived from HTLCs, different authors reported that the chemical composition has a significant influence on the basic properties and consequently on the catalytic activity in transesterification reactions $[9,10,15$, $22,23]$.

The use of commercial calcined $\mathrm{Mg}$,Al-hydrotalcite in the transesterification of rapeseed oil, at $60^{\circ} \mathrm{C}$ with methanol/oil molar ratio of 275 , was first reported by Leclercq et al. [14] with poor results (conversion of $35 \%$ after $22 \mathrm{~h}$ of reaction). On the other hand, Zeng et al. [22] studied the same reaction using Mg,Al-hydrotalcites with different $\mathrm{Mg} / \mathrm{Al}$ molar ratios. According to them, the hydrotalcite catalyst calcined at $500^{\circ} \mathrm{C}$ with $\mathrm{Mg} / \mathrm{Al}$ molar ratio of 3.0 exhibited the highest catalytic activity in the transesterification. In addition, the optimized parameters (methanol/oil molar ratio $=6: 1$, catalyst content $=1.5 \mathrm{wt} . \%$ related to oil amount, stirring speed $=300 \mathrm{rpm}$, reaction temperature $=65^{\circ} \mathrm{C}$, and reaction time $=4 \mathrm{~h}$ ) gave a maximum ester conversion of $90.5 \%$.

The application of Mg,Al-hydrotalcite for biodiesel production from soybean oil was claimed by Siano et al. [17] which found that the activity of the catalyst was affected by the ratio of $\mathrm{Mg} / \mathrm{Al}$, and the most active catalyst was obtained with $\mathrm{Mg} / \mathrm{Al}$ ratio of 3 to 8 . The catalyst was suitable for oils with a high amount of water content $(10,000 \mathrm{ppm})$, and a conversion of $92 \%$ was obtained after $1 \mathrm{~h}$ of reaction time using catalyst content of $5 \mathrm{wt} . \%$ and alcohol/oil weight ratio of 0.45 at reaction temperature of $180^{\circ} \mathrm{C}$.
The use of $\mathrm{MgO}$ (obtained from different precursors) and calcined hydrotalcite $[\mathrm{Al} /(\mathrm{Al}+\mathrm{Mg})=0.20]$ as catalysts for the transesterification of soybean oil with methanol was compared by Di Serio et al. [16]. The results showed a correlation not only with the catalyst basicity, but also with its textural properties, which was dependent on both precursor and preparation method. The calcined hydrotalcite showed the best performance among the studied catalysts, and for the reaction performed at $215-225^{\circ} \mathrm{C}$ using catalyst content of 1 wt.\% and methanol/oil weight ratio of 0.45 the biodiesel yield of $94 \%$ was obtained.

An environmentally benign process for the methanolysis of soybean oil to methyl esters using calcined Mg,Alhydrotalcites as solid base catalysts in a heterogeneous system was developed by Xie et al. [15]. When the reaction was carried out at reflux of methanol, with a molar ratio of soybean oil to methanol of $15: 1$, a reaction time of $9 \mathrm{~h}$, and a catalyst amount of $7.5 \mathrm{wt} . \%$, the oil conversion was $67 \%$. The calcined hydrotalcite with an $\mathrm{Mg} / \mathrm{Al}$ ratio of 3.0 obtained by calcination at $500^{\circ} \mathrm{C}$ was found to be the optimum catalyst that presents the highest basicity and the best catalytic activity for this reaction. The activity of the catalysts for methanolysis reaction was correlated closely with their basicity as determined by the Hammett method.

Antunes et al. [10] used $\mathrm{MgO}, \mathrm{ZnO}, \mathrm{Al}_{2} \mathrm{O}_{3}$, and mixed oxides derived from hydrotalcites-like compounds $(\mathrm{Mg} / \mathrm{Al}$ and $\mathrm{Zn} / \mathrm{Mg} / \mathrm{Al}$ ) as basic solid catalysts on the transesterification of soybean oil with methanol. The results indicated that both $\mathrm{MgO}$ and mixed oxides were efficient to catalyze the reaction with a fatty acid methyl esters yield higher than $60 \%$ at $130^{\circ} \mathrm{C}$. The catalytic performance of the studied catalysts was influenced by their relative basicity, which is affected by the chemical composition. They found methyl esters yields of 70 and $85 \%$ to $\mathrm{MgO}$ and $\mathrm{Mg}$,Al-mixed oxides, respectively, at $130^{\circ} \mathrm{C}$ using an alcohol/oil molar ratio of $55: 1$ and after $7 \mathrm{~h}$.

The catalytic properties of calcined $\mathrm{Li}-\mathrm{Al}, \mathrm{Mg}-\mathrm{Al}$, and $\mathrm{Mg}$-Fe layered double hydroxides (LDHs) were examined by Shumaker et al. [9] for two transesterification reactions, namely, the reaction of glyceryl tributyrate with methanol and the reaction of soybean oil with methanol. Calcined $\left[\mathrm{LiAl}_{2}(\mathrm{OH})_{6}\right]\left(\mathrm{CO}_{3}\right)_{0.5} \cdot n \mathrm{H}_{2} \mathrm{O}$ was an effective catalyst for the transesterification of soybean oil with methanol in which a methyl ester yield of over $80 \%$ was produced when the catalyst was calcined at $450^{\circ} \mathrm{C}$, and the reaction was conducted at a methanol/oil ratio of $15: 1$ with a catalyst loading of $1 \mathrm{wt} . \%$ at reflux temperature for $1 \mathrm{~h}$. While Li-Al catalysts showed high activity in these reactions at reflux temperature of methanol, $\mathrm{Mg}$-Fe and $\mathrm{Mg}$-Al catalysts exhibited much lower methyl ester yields. Temperature-programmed desorption of $\mathrm{CO}_{2}$ measurements revealed the presence of sites of weak, medium, and strong basicity on both $\mathrm{Mg}-\mathrm{Al}$ and $\mathrm{Li}-\mathrm{Al}$ catalysts, the latter showing higher concentrations of medium and strong base sites; by implication, these are the main active sites in transesterification catalyzed by calcined LiAl LDHs. Maximum activity was observed for the Li-Al catalysts when a calcination temperature of $450-500^{\circ} \mathrm{C}$ was applied, corresponding to decomposition of layered double hydroxide to mixed oxide without formation of crystalline lithium aluminate phases. 
The incorporation of $\mathrm{Fe}, \mathrm{Cr}$, and $\mathrm{Ga}$ into $\mathrm{Mg}, \mathrm{Al}-$ hydrotalcite structure was studied by Macala et al. [23] in order to synthesize mixed oxide catalysts with appropriated basicity and activity for the transesterification reaction of glyceryl tributyrate or soybean oil with methanol. Among the catalysts, Fe-doped materials were much more active than the other catalysts for both transesterification reactions. For the transesterification of soybean oil, a conversion of $38 \%$ after $40 \mathrm{~min}$ on-stream at $80^{\circ} \mathrm{C}$ using $1 \mathrm{wt} . \%$ of catalyst was obtained. The presence of strong basic sites was observed on $\mathrm{Fe}, \mathrm{Mg}, \mathrm{Al}$-mixed oxides using a Hammett indicator.

Mixed oxide catalysts derived from Mg-Co-Al-La layered double hydroxide with various $\mathrm{Mg}: \mathrm{Co}: \mathrm{Al}: \mathrm{La}$ ratios were prepared by coprecipitation and calcination by Li et al. [18]. Their catalytic performance as heterogeneous base catalysts for the transesterification of canola oil with ethanol to produce biodiesel was compared over $5 \mathrm{~h}$ in a batch reactor at $200^{\circ} \mathrm{C}$. Amending the catalyst by the addition of $\mathrm{La}$, a possible stabilizer and catalyst, and an increase in $\mathrm{Mg}$, which provides the main base catalyst sites, did not seem to affect the catalytic activity. Experiments using $\mathrm{Mg}_{2} \mathrm{CoAl}$ catalyst are reported, showing the effects of reaction temperature, ethanol/oil molar ratio, particle size, and catalyst stability in the transesterification of canola oil. This material was active for the transesterification of canola oil with ethanol and also stable maintaining its activity after 7 cycles. The kinetics of the transesterification of canola oil catalyzed by $\mathrm{Mg}_{2} \mathrm{CoAl}$ may be modeled as a first-order reaction.

The previous results show that the substitution of $\mathrm{Mg}$ and $\mathrm{Al}$ for other different cations in $\mathrm{Mg}, \mathrm{Al}$-hydrotalcite structure is very interesting due to the possibility of tailoring the acid-base properties of the materials in order to improve its catalytic performance. So, in this work mixed oxides of $\mathrm{Mg}$ and $\mathrm{Al}$ derived from $\mathrm{Mg}$,Al-HTLCs, with molar ratio $\mathrm{M}^{3+} /\left(\mathrm{M}^{2+}+\mathrm{M}^{3+}\right)=0.25$, in which the $\mathrm{Mg}$ or $\mathrm{Al}$ was partially replaced by $\mathrm{Co}, \mathrm{Cu}, \mathrm{Cr}$, or $\mathrm{Fe}$ were comparatively evaluated in the transesterification of soybean oil with methanol to produce biodiesel. The results were interpreted according to the basic and textural properties of these materials.

\section{Experimental}

2.1. Catalyst Preparation. A coprecipitation method was used to synthesize hydrotalcite-like compounds with an $(\mathrm{Al}+$ $\left.\mathrm{T}^{3+}\right) /\left(\left(\mathrm{M}^{2+}+\mathrm{Mg}\right)+\left(\mathrm{Al}+\mathrm{T}^{3+}\right)\right)$ molar ratio of 0.25 . The synthesis gel was prepared by mixing an aqueous solution of metallic cations (solution A) with a highly basic carbonate solution (solution B), under vigorous stirring. Solution A was prepared by dissolving metal nitrates in distilled water in order to obtain total metal cations concentration of $1.5 \mathrm{~mol} \mathrm{~L}^{-1}$. In the preparation of solution $\mathrm{B}$, sodium carbonate and sodium hydroxide were dissolved in distilled water so as to obtain a carbonate concentration of $1 \mathrm{~mol} \mathrm{~L}^{-1}$ and an amount of $\mathrm{OH}^{-}$sufficient to keep the $\mathrm{pH}$ during gel aging at 13 . The gel was aged for $18 \mathrm{~h}$ at $60^{\circ} \mathrm{C}$ (exception for the Cr-containing sample, which was aged for 7 days). The solid obtained was filtered, washed with distilled water $\left(90^{\circ} \mathrm{C}\right)$ until
$\mathrm{pH} 7$, and dried at $80^{\circ} \mathrm{C}$ overnight. The gel composition is the following:

$$
\begin{aligned}
& 0.375 \mathrm{M}\left(\mathrm{NO}_{3}\right)_{2}: 1.875 \mathrm{Mg}\left(\mathrm{NO}_{3}\right)_{2}: 0.75 \mathrm{Al}\left(\mathrm{NO}_{3}\right)_{3}: \\
& 2 \mathrm{Na}_{2} \mathrm{CO}_{3}: 6.75 \mathrm{NaOH}
\end{aligned}
$$

or

$$
\begin{aligned}
& 2.25 \mathrm{Mg}\left(\mathrm{NO}_{3}\right)_{2}: 0.375 \mathrm{~T}\left(\mathrm{NO}_{3}\right)_{3}: 0.375 \mathrm{Al}\left(\mathrm{NO}_{3}\right)_{3}: \\
& 2 \mathrm{Na}_{2} \mathrm{CO}_{3}: 6.75 \mathrm{NaOH},
\end{aligned}
$$

where $\mathrm{M}$ refers to the divalent cation $\left(\mathrm{Co}^{2+}\right.$ or $\left.\mathrm{Cu}^{2+}\right)$ that partially replaces $\mathrm{Mg}^{2+}$ cations and $\mathrm{T}$ refers to trivalent cation $\left(\mathrm{Fe}^{3+}\right.$ or $\left.\mathrm{Cr}^{3+}\right)$ that partially replaces $\mathrm{Al}^{3+}$ cations. The molar ratios $\mathrm{M}^{2+} / \mathrm{Mg}(0.20)$ and $\mathrm{T}^{3+} / \mathrm{Al}(1.0)$ were selected in order to reach a transition metal content close to $11 \%$ (molar base) [24]. An Mg,Al-hydrotalcite with an $\mathrm{Al} /(\mathrm{Mg}+\mathrm{Al})$ molar ratio of 0.25 was also synthesized as reference material using similar procedure $\left(\mathrm{M}^{2+}\right.$ or $\mathrm{T}^{3+}$ cations were not present in solution A).

The precursors samples were named $\mathrm{HT}$ (Mg,Alhydrotalcite), $\mathrm{M}-\mathrm{HT}$, or $\mathrm{T}-\mathrm{HT}$, where $\mathrm{M}$ or $\mathrm{T}$ is the cation that partially replaces $\mathrm{Mg}$ or $\mathrm{Al}$, respectively. The mixed oxides were obtained by calcining HTLCs precursors under dry air from room temperature to $450^{\circ} \mathrm{C}$, at a $1^{\circ} \mathrm{C} \mathrm{min}{ }^{-1}$ heating rate, and keeping at this temperature for $10 \mathrm{~h}$. The calcined samples were named MO, M-MO or T-MO, (M and $\mathrm{T}$ defined previously).

2.2. Physicochemical Characterization. The chemical composition of the HTLCs samples was determined by X-ray fluorescence spectrometry using a Rigaku RIX 3100 spectrometer. In order to identify the crystalline phases formed on both the HTLCs and the mixed oxides, X-ray powder diffractograms were recorded in a Rigaku X-ray diffractometer equipped with a graphite monochromator using $\mathrm{Cu} \mathrm{K} \alpha, 40 \mathrm{kV}$ and $40 \mathrm{~mA}$, in the range $2 \theta$ from $5^{\circ}$ to $80^{\circ}$. The software UnitCell [25] was employed for structural refinement aiming at calculating the lattice parameters, $a$ and $c$. The textural characteristics such as specific surface area (BET) and pore volume (BJH) were determined by $\mathrm{N}_{2}$ adsorption-desorption at $-196^{\circ} \mathrm{C}$ in a Micromeritics ASAP 2000. The HTLCs and mixed oxides samples were previously outgassed at 200 and $450^{\circ} \mathrm{C}$, respectively, overnight.

2.3. Basicity Characterization. The basic properties of the studied catalysts were determined by temperatureprogrammed desorption of $\mathrm{CO}_{2}$ in a unit TPD/TPR equipped with thermal conductivity detector. This technique allows evaluating the distribution of relative strength and density of basic sites present on the materials. The catalysts $(400 \mathrm{mg}$ ) were pretreated under a flow of helium $\left(30 \mathrm{~mL} \mathrm{~min}^{-1}\right)$, starting from room temperature up to $450^{\circ} \mathrm{C}$ at a heating rate of $1^{\circ} \mathrm{C} \mathrm{min}^{-1}$, and then kept at this temperature for $10 \mathrm{~h}$. After activation, the catalysts were cooled down to $100^{\circ} \mathrm{C}$ and treated with a gas mixture containing $4 \% \mathrm{CO}_{2}$ in $\mathrm{He}\left(30 \mathrm{~mL} \mathrm{~min}^{-1}\right)$. Desorption profiles of chemisorbed $\mathrm{CO}_{2}$ were obtained by heating the sample from 100 to $450^{\circ} \mathrm{C}$ under $\mathrm{He}\left(30 \mathrm{~mL} \mathrm{~min}^{-1}\right)$ using 
a heating rate of $10^{\circ} \mathrm{C} \mathrm{min}^{-1}$. The basic sites density was determined according to the ability of the material to retain $\mathrm{CO}_{2}$ molecules during chemical adsorption. The amount of $\mathrm{CO}_{2}$ chemically adsorbed was calculated as the difference between the total and the physically amount adsorbed.

The acid-base properties of the prepared mixed oxides were also determined by the 2-propanol transformation reaction, which was carried out in vapor phase at atmospheric pressure. 2-propanol was fed to the reactor through a saturator held at $20^{\circ} \mathrm{C}$ using $\mathrm{N}_{2}$ as carrier gas. Samples were thermally treated in situ from room temperature up to $450^{\circ} \mathrm{C}$, using a heating rate of $1^{\circ} \mathrm{C} \mathrm{min}^{-1}$, and then kept at this temperature for $10 \mathrm{~h}$. The reaction temperature was $350^{\circ} \mathrm{C}$ and $\mathrm{N}_{2} / 2$-propanol molar ratio equal to 23 . Two sets of experiments were carried out. Firstly the weight hourly space velocity (WHSV, gram of 2-propanol per hour per gram of catalyst) was kept constant at $13.0 \mathrm{~h}^{-1}$, whereas in the second it was varied in order to reach initial isoconversion of $50 \%$. The reaction products were analyzed by online gas chromatography using a CHROMPACK 9000 gas chromatograph, equipped with a $50 \mathrm{~m}$ capillary CPSil5CB and a flame ionization detector.

2.4. Catalytic Tests. The methanolysis of soybean oil was carried out in liquid phase, under autogenous pressure using a $50 \mathrm{~mL}$ stainless steel batch reactor magnetically stirred and heated with a thermostatic bath. Immediately before the runs, the catalysts were calcined according to the procedure previously described in order to obtain mixed oxides. After activation, they were rapidly transferred to the reactor containing the mixture of soybean oil and methanol. Then, the system was heated to reaction temperature, reaching this value quickly. The catalytic performance of the different studied catalysts was evaluated at the following reaction conditions: reaction temperature $=130^{\circ} \mathrm{C}$; methanol $/$ soybean oil molar ratio $=75$; reaction time $=7 \mathrm{~h} ; 5 \mathrm{wt} . \%$ of catalyst (referred to the amount of soybean oil). At the end of each test, the system was rapidly cooled down to room temperature, and the catalyst was separated by centrifugation. The phase with lower density, which contains the methyl ester mixture, was removed, and after methanol elimination it was analyzed by gas chromatography using a VARIAN 3800 chromatograph equipped with a $30 \mathrm{~m}$ Carbowax $20 \mathrm{M}$ capillary column and a flame ionization detector. Methyl heptadecanoate was used as internal standard for the determination of methyl esters yield that is expressed in terms of weight percentage, as described in the European Norm EN14103.

\section{Results and Discussion}

3.1. Physicochemical Characterization. Figure 1 shows the $\mathrm{X}$ ray diffractograms of the as-synthesized HTLC materials in which the crystallographic planes associated with the main peaks are highlighted. Except for the $\mathrm{Cu}$-containing sample, the characteristic pattern of pure hydrotalcite in carbonate form was observed for samples HT, Co-HT, Fe$\mathrm{HT}$, and Cr-HT, suggesting the complete incorporation of the transition metals into the crystalline structure. For sample

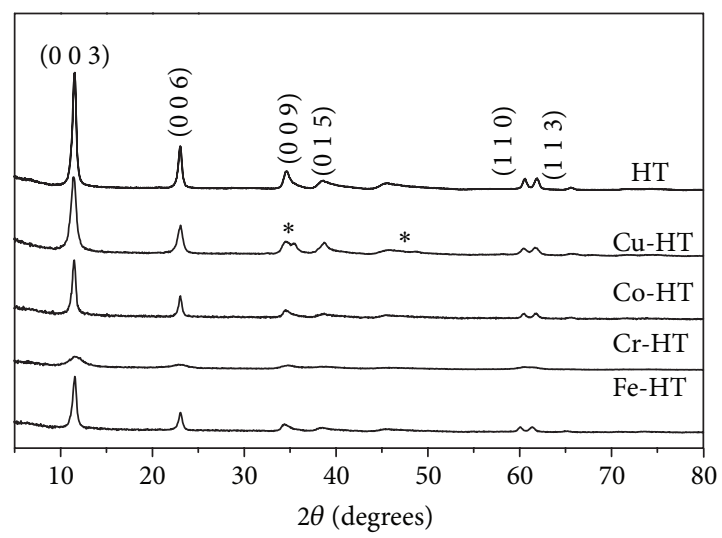

FIGURE 1: X-ray diffraction patterns of the as-synthesized HTLCs precursors. $(*) \mathrm{CuO}$-tenorite.

$\mathrm{Cu}-\mathrm{HT}$, diffraction lines at $2 \theta$ equal to $35.45^{\circ}$ and $48.75^{\circ}$, corresponding to $\mathrm{CuO}$-tenorite $(*)$ [26] were observed along with the hydrotalcite pattern. Although a large aging time (7 days) was used to synthesize the chromium-containing sample (Cr-HT), a very low crystallinity was noted indicating slower crystallization kinetics when compared to the other samples.

The peaks associated to planes ( $\left(\begin{array}{lll}0 & 0 & 3\end{array}\right),\left(\begin{array}{lll}0 & 0 & 6\end{array}\right),\left(\begin{array}{lll}1 & 1 & 0\end{array}\right)$, and $\left(\begin{array}{lll}1 & 1 & 3\end{array}\right)$ were used to calculate the lattice parameters, $a$ and $c$, typical of hydrotalcite structures with rhombohedral $3 \mathrm{R}$ symmetry. These parameters and the ionic radius of the cations present in each HTLC structure are shown in Table 1. Comparing the values of parameter $a$, which is a function of the cation-cation distance in the hydroxide layers [27], it can be observed that their differences are compatible with those existent between $\mathrm{Mg}^{2+}$ or $\mathrm{Al}^{3+}$ ionic radius and those of the transition metal di- or trivalent cations. This indicates that these transition metal cations have isomorphously replaced $\mathrm{Mg}^{2+}$ or $\mathrm{Al}^{3+}$ in the HTLC structure. On the other hand, the values of parameter $c$, which is related to the layer thickness (brucite-like sheet plus an interlayer), probably reflect the influence of various factors such as the amount of interlayer water, the size of the interlayer anion and of $\mathrm{M}^{2+}$ $\mathrm{M}^{3+}$ cations, and the strength of electrostatic attractive forces between layer and interlayer $[27,28]$. As to the crystallite size, estimated using Scherrer equation considering the line broadening associated to $\left(\begin{array}{lll}0 & 0 & 3\end{array}\right)$ basal reflection, the results in Table 1 confirm the lower crystallite size of sample $\mathrm{Cr}-\mathrm{HT}$ which can be related to the lower crystallization rate of this sample.

The chemical composition and textural properties of as-synthesized HTLCs are shown in Table 2. The metallic cations incorporation has occurred as expected, since the chemical composition of the samples was quite similar to that of the corresponding synthesis gel. Concerning the textural characteristics, the partial replacement of $\mathrm{Mg}$ or $\mathrm{Al}$ by $\mathrm{Cu}, \mathrm{Co}$, or $\mathrm{Fe}$ did not have a significant effect on BET specific surface area when compared to that of pure $\mathrm{Mg}, \mathrm{Al}$-hydrotalcite (sample HT), but mesoporous volume has increased. On the other hand, the highest surface area of 
TABLE 1: Lattice parameters of the as-synthesized HTLCs.

\begin{tabular}{lcccc}
\hline Sample & $a$ & $c$ & Crystallite size $(\AA)$ & $\begin{array}{c}\text { Ionic radius }(\AA) \\
{[1]}\end{array}$ \\
\hline HT & 3.0536 & 23.1392 & 178 & $\mathrm{Mg}^{2+}=0.65$ \\
$\mathrm{Al}^{3+}=0.50$ \\
Cu-HT & 3.0602 & 23.3020 & 124 & $\mathrm{Cu}^{2+}=0.69$ \\
Co-HT & 3.0596 & 23.2677 & 176 & $\mathrm{Co}^{2+}=0.74$ \\
Fe-HT & 3.0791 & 23.0999 & 178 & $\mathrm{Fe}^{3+}=0.64$ \\
Cr-HT & - & - & 52 & $\mathrm{Cr}^{3+}=0.69$ \\
\hline
\end{tabular}

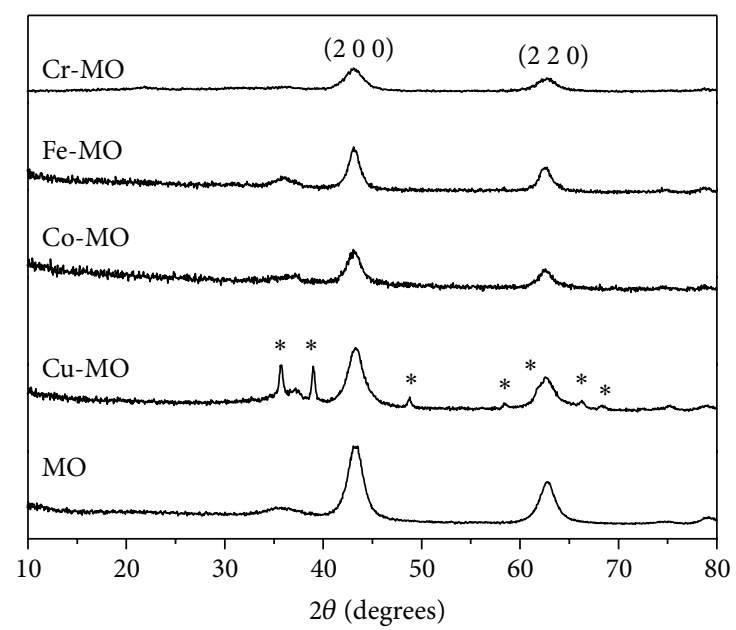

Figure 2: X-ray diffraction patterns of the mixed oxides derived from HTLCs after calcination at $450^{\circ} \mathrm{C}$. (*) CuO-tenorite.

sample Cr-HT, compared to the other synthesized materials, could be reflecting its smallest crystallite size.

Upon calcination at $450^{\circ} \mathrm{C}$, a poorly crystallized $\mathrm{Mg}(\mathrm{Al}) \mathrm{O}$ with a periclase-type structure $\left(2 \theta=43.40^{\circ}\right.$ and $62.90^{\circ}$, corresponding to the ( $\left(\begin{array}{lll}2 & 0 & 0\end{array}\right)$ and ( $\left(\begin{array}{lll}2 & 2 & 0\end{array}\right)$ reflections $)$ [26] in which the oxides of the transition metals were dispersed was observed due to the collapse of the layered structure of HTLCs. No spinel-type phase was detected in the X-ray diffractograms (Figure 2). For sample $\mathrm{Cu}-\mathrm{MO}$, characteristic peaks associated to the $\mathrm{CuO}$-tenorite phase were observed along with the $\mathrm{Mg}(\mathrm{Cu}, \mathrm{Al}) \mathrm{O}$-periclase phase. The oxide phase was already present in the precursor material and became more evident after thermal treatment at $450^{\circ} \mathrm{C}$. This result differs from those of Chmielarz et al. [29] which studied a $\mathrm{Cu}, \mathrm{Mg}, \mathrm{Al}$-hydrotalcite with similar composition and detected the segregation of a $\mathrm{CuO}$-phase only for the sample calcined at $1000^{\circ} \mathrm{C}$. On the other hand, X-ray diffractograms of samples Co-MO, Cr-MO, and Fe-MO indicate that cobalt, chromium, and iron oxides are well dispersed in the $\mathrm{Mg}(\mathrm{Al}) \mathrm{O}$ phase.

Textural analysis of the samples calcined under air at $450^{\circ} \mathrm{C}$ indicated that they are mesoporous mixed oxides whose main textural properties are shown in Table 3. The incorporation of $\mathrm{Cu}, \mathrm{Co}$, and $\mathrm{Fe}$ in the HTLC structure originated mixed oxides with smaller BET specific area and pore volume than those of the corresponding $\mathrm{Mg}, \mathrm{Al}$-mixed oxide (MO). Similar trends are reported by Chmielarz et al.

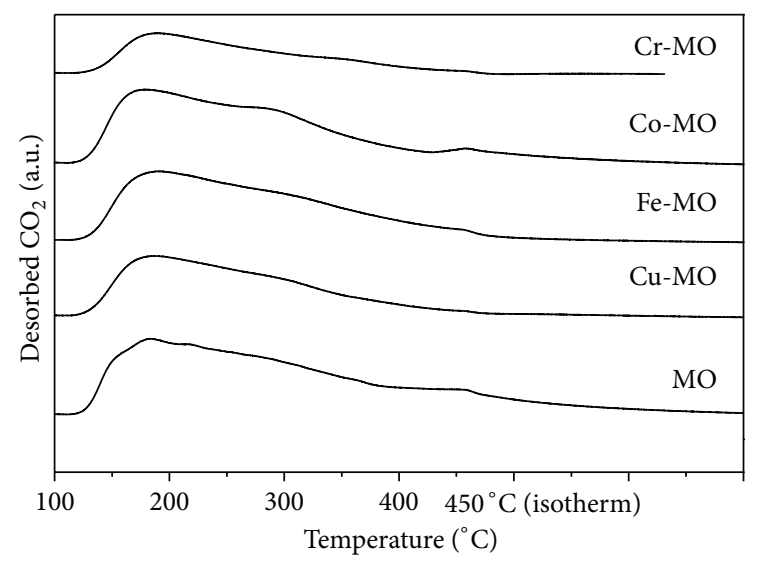

FIGURE 3: Desorption profiles of chemisorbed $\mathrm{CO}_{2}\left(\mathrm{CO}_{2}\right.$-TPD).

[29]. However, for Cr-mixed oxide sample the specific area is higher and the pore volume is smaller than those of $\mathrm{Mg}, \mathrm{Al}-$ mixed oxide. The incorporation of $\mathrm{Cu}$ led to the sample with the lowest values of specific area and mesopores volume which could be associated to a partial blockage of the pores due to the presence of the segregated phase coexisting with the periclase-type phase.

3.2. Basicity Characterization. The profiles of $\mathrm{CO}_{2}$ temperature-programmed desorption are shown in Figure 3. It is observed that all profiles are characterized by the presence of a broad peak covering a wide range of temperatures, suggesting a wide distribution of basic strength of surface sites. Therefore, it can be concluded that the partial substitution of $\mathrm{Mg}$ or $\mathrm{Al}$ for different ions of transition metals had no significant effect on the distribution of strength of basic sites. Valente et al. [30] observed similar $\mathrm{CO}_{2}$ profiles for $\mathrm{Mg}, \mathrm{Al}$-mixed oxides where $\mathrm{Mg}$ or $\mathrm{Al}$ were substituted for $\mathrm{Ni}, \mathrm{Zn}, \mathrm{Cu}$, and $\mathrm{Fe}$ indicating a wide strength distribution of basic sites.

The total basic site density of the studied catalysts was determined by temperature-programmed desorption of $\mathrm{CO}_{2}$ and expressed as the amount of chemisorbed $\mathrm{CO}_{2}$. The results are shown in Figure 4. It is observed that, while the incorporation of Co and Fe slightly decreased the basic site density, the presence of $\mathrm{Cu}$ and $\mathrm{Cr}$ produced samples with much lower basicity. The reduction in total basic sites density upon the replacement of $\mathrm{Mg}$ and/or $\mathrm{Al}$ by transition metal was also reported in the literature $[30,31]$. However, the magnitude of the observed effect varies depending on the metal content and methodology of sample preparation.

Considering that the incorporation of transition metals also influenced BET specific area and volume of mesopores, attempts were made to correlate the density of basic sites with textural properties. As shown in Figure 5, there is a direct correlation between the volume of mesopores and the density of basic sites.

The transformation of 2-propanol is often used as a model reaction for the determination of the acid-base properties of solid catalysts. This transformation occurs via elimination reactions, dehydration, and dehydrogenation, for example, 
TABLE 2: Chemical composition and textural characteristics of HTLCs.

\begin{tabular}{lcccc}
\hline Sample & \multicolumn{2}{c}{ Molar composition } & $S_{\text {BET }}\left(\mathrm{m}^{2} \mathrm{~g}^{-1}\right)$ & $V_{\text {meso }}\left(\mathrm{cm}^{3} \mathrm{~g}^{-1}\right)^{\mathrm{a}}$ \\
\hline $\mathrm{Mg} / \mathrm{Al}$ & $6.0 / 2.0$ & Sample & 71 & 0.378 \\
$\mathrm{Cu} / \mathrm{Mg} / \mathrm{Al}$ & $1.0 / 5.0 / 2.0$ & $6.06 / 1.94$ & 76 & 0.413 \\
$\mathrm{Co} / \mathrm{Mg} / \mathrm{Al}$ & $1.0 / 5.0 / 2.0$ & $0.81 / 5.25 / 1.94$ & 69 & 0.489 \\
$\mathrm{Cr} / \mathrm{Mg} / \mathrm{Al}$ & $1.0 / 6.0 / 1.0$ & $0.95 / 5.11 / 1.94$ & 170 & 0.190 \\
$\mathrm{Fe} / \mathrm{Mg} / \mathrm{Al}$ & $1.0 / 6.0 / 1.0$ & $0.88 / 6.12 / 1.00$ & 71 & 0.490 \\
\hline
\end{tabular}

${ }^{\mathrm{a} C a l c u l a t e d}$ by BJH method.

TABLE 3: Textural characteristics of mixed oxides.

\begin{tabular}{lcc}
\hline Sample & $S_{\text {BET }}\left(\mathrm{m}^{2} \mathrm{~g}^{-1}\right)$ & $V_{\text {meso }}\left(\mathrm{cm}^{3} \mathrm{~g}^{-1}\right)^{\mathrm{a}}$ \\
\hline MO & 213 & 0.747 \\
Cu-MO & 114 & 0.495 \\
Co-MO & 179 & 0.656 \\
Cr-MO & 253 & 0.163 \\
Fe-MO & 140 & 0.617 \\
\hline
\end{tabular}

${ }^{\mathrm{a}}$ Calculated by BJH method.

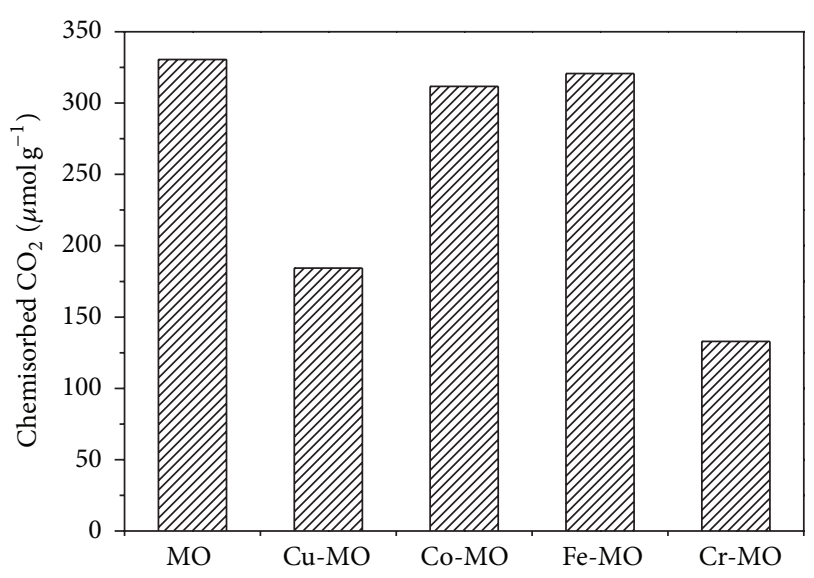

FIGURE 4: Basic site density of studied catalysts measured by $\mathrm{CO}_{2}{ }^{-}$ TPD.

which can occur through different mechanisms depending on the nature of the studied materials [32]. However, the presence of redox sites can also promote dehydrogenation of 2-propanol. Concerning the dehydration reaction, most primary and secondary alcohols react through an E2 concerted mechanism, involving both acid and basic sites of the solid, and leading to olefin and ether formation. However, alcohol dehydration can also proceed through the E1b mechanism involving an intermediate carbanion on strong basic solids which possess acid/base sites with imbalanced strength. On the other hand, the dehydrogenation reaction occurs over strongly basic solid catalysts through an E1b mechanism involving the same intermediate carbanion that forms olefins, but in this case, the ketone is formed by an $\alpha$-hydrogen abstraction. Another alternative mechanism for dehydrogenation is an oxidative process in which redox centers and molecular or lattice oxygen are required. When

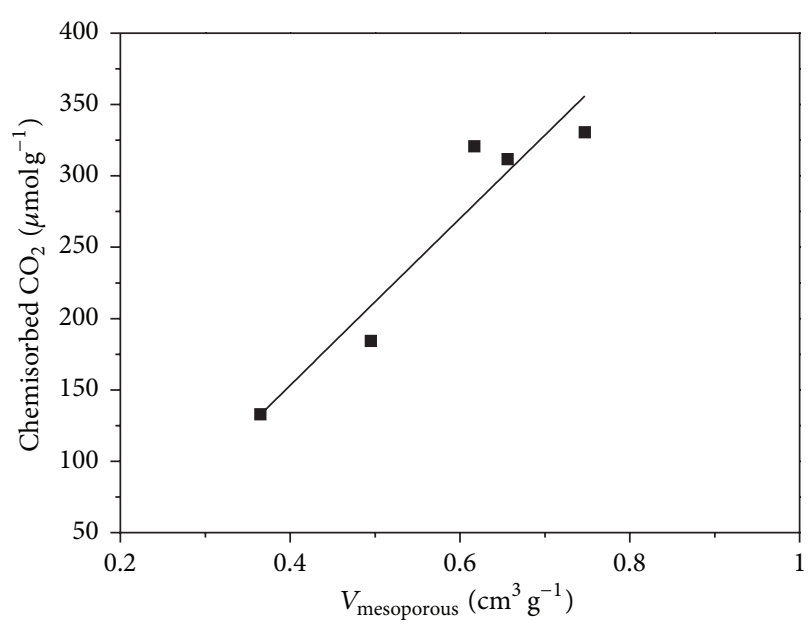

FIGURE 5: Relationship between basic site density measured by $\mathrm{CO}_{2}$ TPD and mesoporous volume.

2-propanol is used as a model probe, the possible reaction products are propene, di-isopropyl ether, and acetone.

Figure 6 shows 2-propanol conversion behavior with time-on-stream for the mixed oxides obtained after calcination at $450^{\circ} \mathrm{C}$. For the experimental conditions used in this work, all samples were active and showed a slight deactivation. According to these results, $\mathrm{Cu}-\mathrm{MO}$ presents the higher density of sites capable of catalyzing the reactions of 2-propanol, and the following sequence of activity could be established: $\mathrm{Cu}-\mathrm{MO}>\mathrm{Cr}-\mathrm{MO}>\mathrm{Co}-\mathrm{MO}>\mathrm{Fe}-\mathrm{MO}$. This trend differs significantly from that found by TPD of $\mathrm{CO}_{2}$ reinforcing the difficulty in the selection of an appropriate technique to characterize the basic properties of solid catalysts.

In order to investigate the influence of the presence of transition metals on the nature of surface sites, the selectivity of the catalysts was analyzed in a second set of experiments carried out at initial isoconversion conditions (Figure 7). Only acetone and propene were detected as reaction products, and their selectivities were determined at 2-propanol conversion of approximately 50\%. Over Cu-MO and Co-MO the selectivity to acetone was very high mainly indicating the presence of strong basic sites and/or redox centers. In the case of $\mathrm{Cr}-\mathrm{MO}$ and $\mathrm{Fe}-\mathrm{MO}$ both acetone and propene were observed showing that these samples presented strong basic sites, acid sites, and possibly redox centers. Our results are in agreement with those of Valente et al. [30] that have studied 


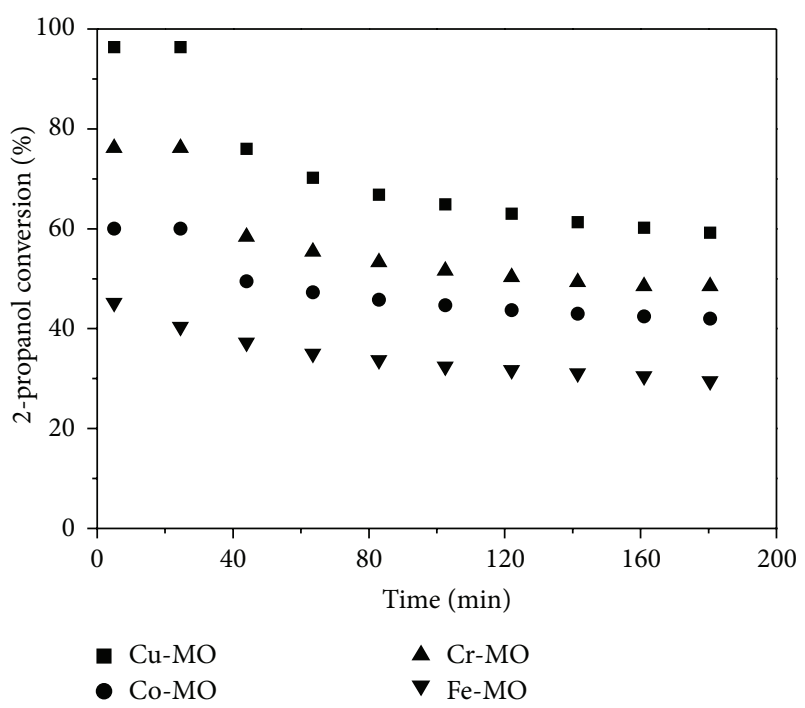

FIgURE 6: Conversion of 2-propanol as a function of time-onstream for the mixed oxides obtained after calcination to $450^{\circ} \mathrm{C}$ (atmospheric pressure, $T=350^{\circ} \mathrm{C} ; \mathrm{N}_{2} / 2$-propanol $=23$; WHSV $=$ $\left.13.0 \mathrm{~h}^{-1}\right)$.

the conversion of 4-methylpentan-2-ol into 4-methylpentan2-one (MIBK) and olefins via dehydrogenation and dehydration, respectively, over $\mathrm{MgZnAl}-, \mathrm{MgCuAl}=, \mathrm{MgNiAl}_{-}$, and $\mathrm{MgFeAl}$-mixed oxides. They verified that $\mathrm{MgCuAl}$ produced only MIBK, while $\mathrm{MgFeAl}$ catalyzed the formation of olefins and MIBK. Although the transformation of 2-propanol is largely used as a model reaction to study acid-base properties, it is not easy to clearly identify the nature or strength of the acid-base sites, especially when reducible metals are present in the sample. The elucidation of the role of basic or redox sites on the dehydrogenation of 2-propanol is still difficult and not deeply studied. Carriazo et al. [33] have studied the acid-base and redox properties of amorphous magnesium and zinc molybdates derived from $\mathrm{Mg}, \mathrm{Al}-$ and $\mathrm{Zn}, \mathrm{Al}$-heptamolybdate layered double hydroxides using Fourier transform infrared spectroscopy (FTIR) to monitor the adsorption of 2-propanol, acetic acid, and acetone on those materials. According to their results a distinction between the acid-base mechanism and the redox one for 2propanol dehydrogenation could not be achieved.

3.3. Catalytic Results. Methyl esters of palmitic (C16), stearic (C18), oleic (C18:1), and linoleic (C18:2) acids were the main products formed in the soybean oil transesterification with methanol. The reaction scheme is shown in Figure 8. The transesterification process is a sequence of three reversible consecutive reactions in which mono- and diglycerides are intermediates. According to the stoichiometry, the reaction occurs between $1 \mathrm{~mol}$ of triglyceride and $3 \mathrm{~mol}$ of alcohol. However, an excess of alcohol is generally used to increase the esters yield and to facilitate glycerol separation.

The catalytic performance of the studied solids was compared at $130^{\circ} \mathrm{C}$ using a methanol/oil molar ratio of 75 . The results, expressed as fatty acid methyl esters (FAME) yield

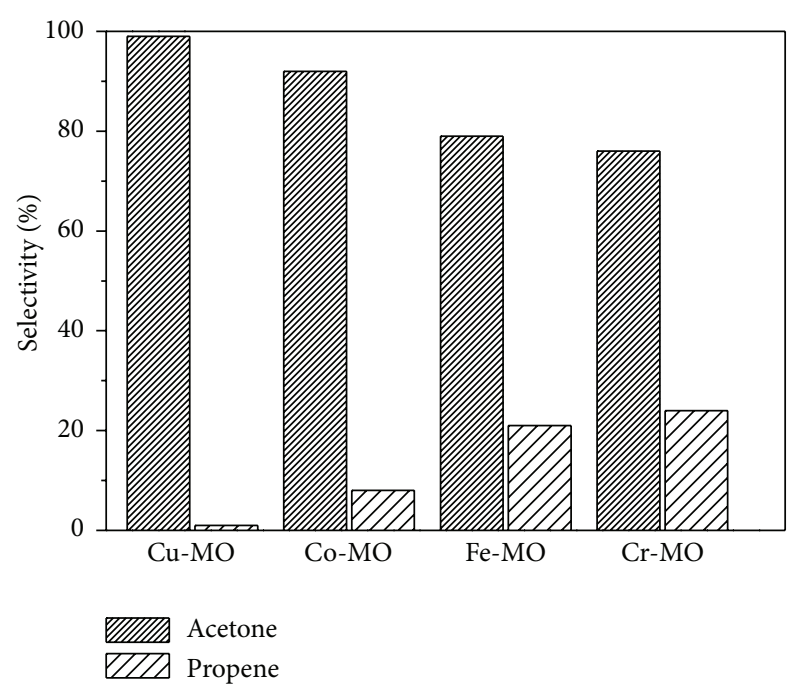

FIGURE 7: Selectivity results for 2-propanol transformation at isoconversion of $50 \%$ (atmospheric pressure, $T=350^{\circ} \mathrm{C} ; \mathrm{N}_{2} / 2$-propanol $=23$; reaction time $=5 \mathrm{~min}$ ).

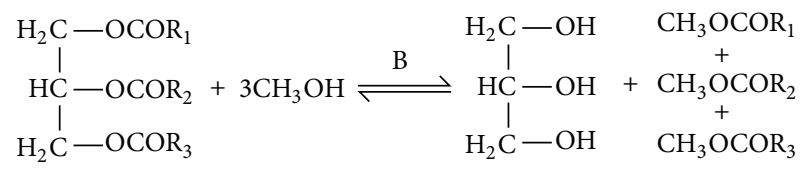

Triglyceride Methanol Glycerin Mixture of FAME

where

$\mathrm{R}_{1}, \mathrm{R}_{2}, \mathrm{R}_{3}=\mathrm{C} 16, \mathrm{C} 18, \mathrm{C} 18: 1, \mathrm{C} 18: 2$

$\mathrm{B}=$ basic solid catalyst

FIGURE 8: Reaction scheme for the transesterification of soybean oil with methanol.

(\%), are presented in Figure 9. No reaction was observed in the absence of catalyst at $130^{\circ} \mathrm{C}$. These results indicate that the mixed oxides samples are active in the transesterification of soybean oil with methanol; that is, they have sufficient basicity to catalyze the reaction. The following sequence of catalytic activity could be observed: $\mathrm{Cr}-\mathrm{MO}<\mathrm{Co}-\mathrm{MO}<\mathrm{Cu}-$ $\mathrm{MO}<\mathrm{Fe}-\mathrm{MO}<\mathrm{MO}$. The methyl esters yield correlated well to the volume of mesopores variation as shown in Figure 10. However, the attempt to correlate the catalytic performance of the transition metal-mixed oxides for transesterification reaction and their basic properties failed. Thus, for the basic site density measured by $\mathrm{CO}_{2}$-TPD the results presented in Figure 11 only suggest a slight trend of increase in biodiesel yield with increasing density of basic sites, while no clear correlation was observed between the catalytic behavior of the transition metal mixed oxides studied in this work for the 2-propanol transformation and the transesterification of soybean oil and methanol. This fact could be related to the influence of the redox mechanism on 2-propanol transformation but not on the transesterification reaction. The characterization of basic properties is still a challenge due to the difficulty of selecting the appropriated technique, 


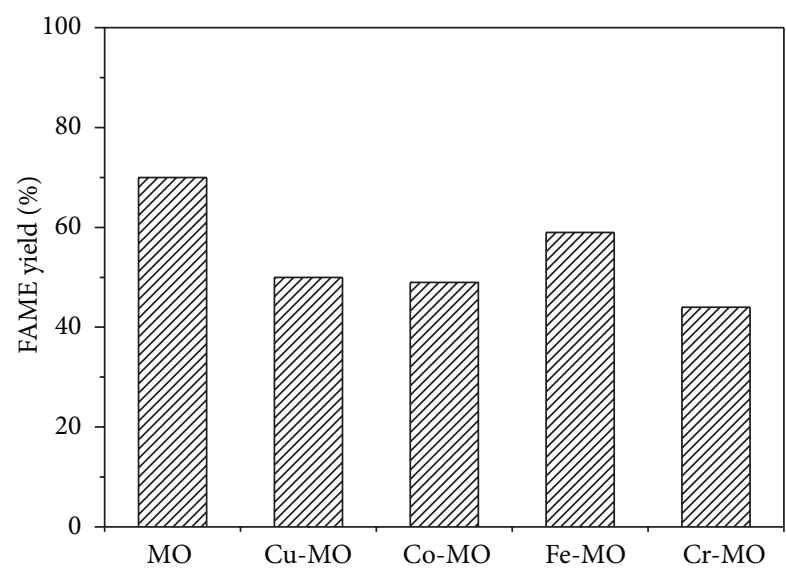

FIGURE 9: Methyl esters yield for the studied catalysts $\left(\mathrm{R}_{\mathrm{CH}_{3} \mathrm{OH} / \mathrm{oil}}=\right.$ $75 ; T=130^{\circ} \mathrm{C} ; t=7 \mathrm{~h} ; 5 \mathrm{wt} . \%$ of catalyst).

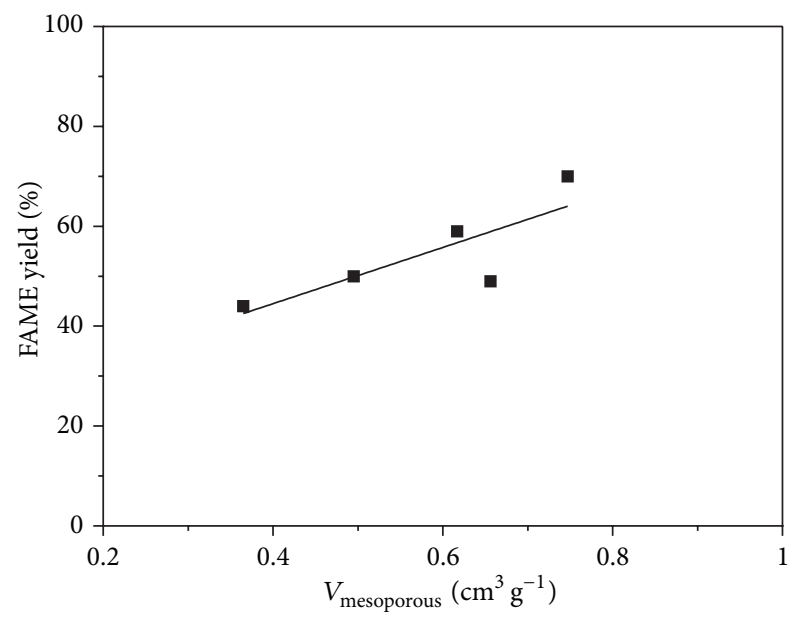

FIGURE 10: Relationship between the activity (expressed by methyl esters yield) and mesoporous volume.

probe molecule, or model reaction that can represent the same catalytic mechanism of the studied reaction.

The comparison of the catalytic results for the transesterification of soybean oil and methanol obtained in this study with those recently reported is not easy because just a few published results using $\mathrm{Mg}, \mathrm{Al}$-mixed oxides containing transition metals for transesterification reaction are available. Macala et al. [23] have depicted that the partial substitution of $\mathrm{Al}$ by Fe generates a mixed oxide more active than an $\mathrm{Mg}, \mathrm{Al}-$ mixed oxide for the reaction between glyceryl tributyrate and methanol at $60^{\circ} \mathrm{C}$ using $1 \mathrm{wt} . \%$ of catalyst and a methanol to glyceryl tributyrate molar ratio of 6 . However, the authors have highlighted the low activity achieved by their Mg,Almixed oxide. It is also necessary to point out that the transesterification of glyceryl tributyrate and methanol is a model reaction using a simpler ester to model triglycerides. A good performance of a Co, $\mathrm{Mg}$, Al-mixed oxide $\left(\mathrm{M}^{2+} / \mathrm{M}^{3+}\right.$ molar ratio $=3$ ) has been described by Li et al. [18] in the transesterification of canola oil and ethanol, but in this case a comparison with the results of the present work is

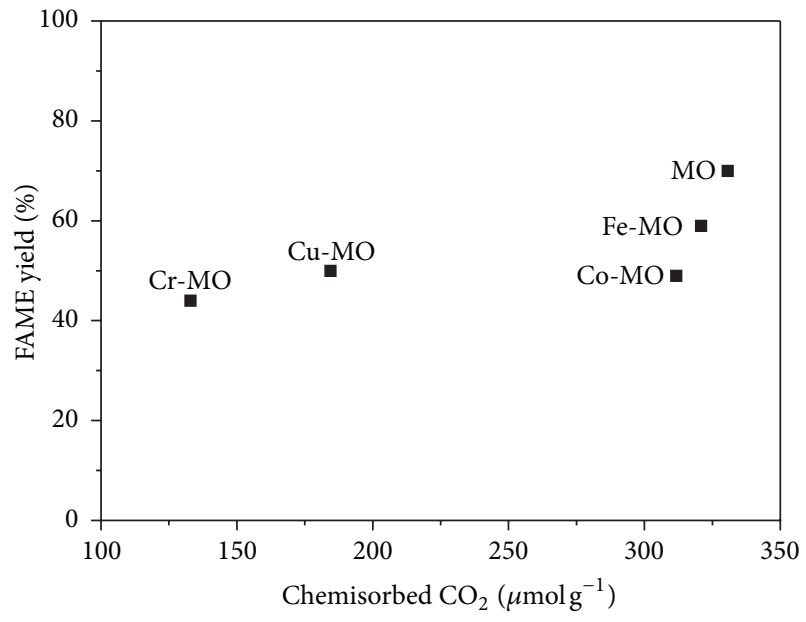

FIGURE 11: Relationship between the activity (expressed by methyl esters) and basic site density of the catalysts.

hampered by the fact that the $\mathrm{Mg}, \mathrm{Al}$-mixed oxide prepared by the authors turned into a gel-like phase in the presence of the reaction medium making the catalyst recovery difficult. Although these authors $[18,23]$ mentioned a better catalytic behavior for Mg,Al-mixed oxides containing transition metals, both of them reported unusual performance for their Mg,Al-mixed oxides. On the other hand, Pavel et al. [31] have synthesized MMgAlO mixed oxide catalysts $(\mathrm{M}=\mathrm{Mn}$, $\mathrm{Fe}, \mathrm{Co}, \mathrm{Ni}, \mathrm{Cu}$, and $\mathrm{Zn}$ ) derived from the corresponding layered double hydroxide by thermal decomposition. These mixed oxides were tested as catalyst for cyanoethylation of methanol, which first reaction step is the abstraction of a proton from the hydroxyl group of methanol by basic sites producing an alkoxide anion. The authors reported that reaction conversion decreased after introduction of transition metal cations. This is the same trend observed in our work. Although Pavel et al. [31] have studied a different reaction, the first step of both cyanoethylation of methanol and transesterification of soybean oil and methanol is the same.

\section{Conclusions}

The mixed oxides derived from $\mathrm{Mg}$,Al-HTLC in which the $\mathrm{Mg}$ or $\mathrm{Al}$ was partially replaced by a transition metal $(\mathrm{Cu}, \mathrm{Co}$, $\mathrm{Fe}$, or $\mathrm{Cr}$ ) were prepared, characterized, and tested as catalysts for the transesterification of soybean oil with methanol. The results showed that the incorporation of transition metal influences both the textural characteristics and the density of basic sites present in catalysts, although not having a significant effect on the distribution of basic strength of these sites. All tested catalysts were active in the reaction studied, and the following sequence of catalytic activity was found: $\mathrm{Cr}-$ $\mathrm{MO}<\mathrm{Co}-\mathrm{MO}<\mathrm{Cu}-\mathrm{MO}<\mathrm{Fe}-\mathrm{MO}<\mathrm{MO}$. The incorporation of transition metal did not improve the catalytic activity of $\mathrm{Mg}$,Al-mixed oxide. When the catalytic performance is analyzed according to physicochemical characterization, it appears that these results can be explained by catalyst texture and expressed by the volume of mesopores. 


\section{Acknowledgments}

The authors thank CNPq and CENPES/PETROBRAS for financial support. Paula M. Veiga would like to thank CAPES for the Master's Scholarship, and Cristiane Henriques thanks PROCIENCIA Program of Universidade do Estado do Rio de Janeiro for the financial support.

\section{References}

[1] F. Cavani, F. Trifirò, and A. Vaccari, "Hydrotalcite-type anionic clays: preparation, properties and applications," Catalysis Today, vol. 11, no. 2, pp. 173-301, 1991.

[2] D. Tichit, M. H. Lhouty, A. Guida et al., "Textural properties and catalytic activity of hydrotalcites," Journal of Catalysis, vol. 151, no. 1, pp. 50-59, 1995.

[3] I. Di Cosimo, V. K. Diez, M. Xu et al., "Structure and surface and catalytic properties of Mg-Al basic oxides," Journal of Catalysis, vol. 178, no. 2, pp. 499-510, 1998.

[4] A. Corma, S. Iborra, J. Primo, and F. Rey, "One-step synthesis of citronitril on hydrotalcite derived base catalysts," Applied Catalysis A, vol. 114, no. 2, pp. 215-225, 1994.

[5] M. J. Climent, A. Corma, S. Iborra, and J. Primo, "Base catalysis for fine chemicals production: claisen-schmidt condensation on zeolites and hydrotalcites for the production of chalcones and flavanones of pharmaceutical interest," Journal of Catalysis, vol. 151, no. 1, pp. 60-66, 1995.

[6] M. J. Climent, A. Corma, S. Iborra, K. Epping, and A. Velty, "Increasing the basicity and catalytic activity of hydrotalcites by different synthesis procedures," Journal of Catalysis, vol. 225, no. 2, pp. 316-326, 2004.

[7] C. N. Pérez, C. A. Pérez, C. A. Henriques et al., "Hydrotalcites as precursors for $\mathrm{Mg}$, Al-mixed oxides used as catalysts on the aldol condensation of citral with acetone," Applied Catalysis A, vol. 272, no. 1-2, pp. 229-240, 2004.

[8] C. O. Veloso, C. A. Henriques, A. G. Dias, and J. L. F. Monteiro, "Condensation of glyceraldehyde acetonide and acetone over basic catalysts," Catalysis Today, vol. 107-108, pp. 294-301, 2005.

[9] J. L. Shumaker, C. Crofcheck, S. A. Tackett et al., "Biodiesel synthesis using calcined layered double hydroxide catalysts," Applied Catalysis B, vol. 82, no. 1-2, pp. 120-130, 2008.

[10] W. M. Antunes, C. D. O. Veloso, and C. A. Henriques, "Transesterification of soybean oil with methanol catalyzed by basic solids," Catalysis Today, vol. 133-135, no. 1-4, pp. 548-554, 2008.

[11] E. Crabbe, C. Nolasco-Hipolito, G. Kobayashi, K. Sonomoto, and A. Ishizaki, "Biodiesel production from crude palm oil and evaluation of butanol extraction and fuel properties," Process Biochemistry, vol. 37, no. 1, pp. 65-71, 2001.

[12] H. J. Kim, B. S. Kang, M. J. Kim et al., "Transesterification of vegetable oil to biodiesel using heterogeneous base catalyst," Catalysis Today, vol. 93-95, pp. 315-320, 2004.

[13] G. Arzamendi, I. Campo, E. Arguiñarena, M. Sánchez, M. Montes, and L. M. Gandía, "Synthesis of biodiesel from sunflower oil with silica-supported $\mathrm{NaOH}$ catalysts," Journal of Chemical Technology and Biotechnology, vol. 83, no. 6, pp. 862870, 2008.

[14] E. Leclercq, A. Finiels, and C. Moreau, "Transesterification of rapeseed oil in the presence of basic zeolites and related solid catalysts," Journal of the American Oil Chemists' Society, vol. 78, no. 11, pp. 1161-1165, 2006.
[15] W. Xie, H. Peng, and L. Chen, "Calcined Mg-Al hydrotalcites as solid base catalysts for methanolysis of soybean oil," Journal of Molecular Catalysis A, vol. 246, no. 1-2, pp. 24-32, 2006.

[16] M. Di Serio, M. Ledda, M. Cozzolino, G. Minutillo, R. Tesser, and E. Santacesaria, "Transesterification of soybean oil to biodiesel by using heterogeneous basic catalysts," Industrial and Engineering Chemistry Research, vol. 45, no. 9, pp. 3009-3014, 2006.

[17] D. Siano, M. Nastasi, E. Santacesaria et al., "Process for producing esters from vegetable oils or animal fats using heterogeneous catalysts," PCT Application No. WO2006/050925, 2006.

[18] E. Li, Z. P. Xu, and V. Rudolph, "MgCoAl-LDH derived heterogeneous catalysts for the ethanol transesterification of canola oil to biodiesel," Applied Catalysis B, vol. 88, no. 1-2, pp. 42-49, 2009.

[19] A. K. Singh and S. D. Fernando, "Transesterification of soybean oil using heterogeneous catalysts," Energy and Fuels, vol. 22, no. 3, pp. 2067-2069, 2008.

[20] S. Yan, H. Lu, and B. Liang, "Supported $\mathrm{CaO}$ catalysts used in the transesterification of rapeseed oil for the purpose of biodiesel production," Energy and Fuels, vol. 22, no. 1, pp. 646-651, 2008.

[21] Z. Yang and W. Xie, "Soybean oil transesterification over zinc oxide modified with alkali earth metals," Fuel Processing Technology, vol. 88, no. 6, pp. 631-638, 2007.

[22] H. Y. Zeng, Z. Feng, X. Deng, and Y. Q. Li, "Activation of MgAl hydrotalcite catalysts for transesterification of rape oil," Fuel, vol. 87, no. 13-14, pp. 3071-3076, 2008.

[23] G. S. Macala, A. W. Robertson, C. L. Johnson et al., “Transesterification catalysts from iron doped hydrotalcite-like precursors: solid bases for biodiesel production," Catalysis Letters, vol. 122, no. 3-4, pp. 205-209, 2008.

[24] A. E. Palomares, J. M. López-Nieto, F. J. Lázaro, A. López, and A. Corma, "Reactivity in the removal of $\mathrm{SO}_{2}$ and $\mathrm{NO}_{x}$ on $\mathrm{Co} / \mathrm{Mg} / \mathrm{Al}$ mixed oxides derived from hydrotalcites," Applied Catalysis B, vol. 20, no. 4, pp. 257-266, 1999.

[25] T. J. B. Holland and S. A. T. Redfern, "Unit cell refinement from powder diffraction data: the use of regression diagnostics," Mineralogical Magazine, vol. 61, no. 1, pp. 65-77, 1997.

[26] ICDD PDF-2 Database, International Centre for Diffraction Data, Newton Square, Pa, USA, 1998.

[27] I. Pausch, H. H. Lohse, K. Schurmann, and R. Allmann, "Synthesis of disordered and Al-rich hydrotalcite-like compounds," Clays \& Clay Minerals, vol. 34, no. 5, pp. 507-510, 1986.

[28] S. Velu, N. Shah, T. M. Jyothi, and S. Sivasanker, "Effect of manganese substitution on the physicochemical properties and catalytic toluene oxidation activities of $\mathrm{Mg}$-Al layered double hydroxides," Microporous and Mesoporous Materials, vol. 33, no. 1-3, pp. 61-75, 1999.

[29] L. Chmielarz, P. Kuśtrowski, A. Rafalska-Łasocha, and R. Dziembaj, "Influence of $\mathrm{Cu}, \mathrm{Co}$ and $\mathrm{Ni}$ cations incorporated in brucite-type layers on thermal behaviour of hydrotalcites and reducibility of the derived mixed oxide systems," Thermochimica Acta, vol. 395, no. 1-2, pp. 225-236, 2003.

[30] J. S. Valente, J. Hernandez-Cortez, M. S. Cantu, G. Ferrat, and E. López-Salinas, "Calcined layered double hydroxides Mg-Me-Al (Me: $\mathrm{Cu}, \mathrm{Fe}, \mathrm{Ni}, \mathrm{Zn}$ ) as bifunctional catalysts," Catalysis Today, vol. 150, no. 3-4, pp. 340-345, 2010.

[31] O. Pavel, D. Tichit, and I. Marcu, "Acido-basic and catalytic properties of transition-metal containing $\mathrm{Mg}$ - $\mathrm{Al}$ hydrotalcites and their corresponding mixed oxides," Applied Clay Science, vol. 61, pp. 52-58, 2012. 
[32] A. Gervasini, J. Fenyvesi, and A. Auroux, "Study of the acidic character of modified metal oxide surfaces using the test of isopropanol decomposition," Catalysis Letters, vol. 43, no. 1-2, pp. 219-228, 1997.

[33] D. Carriazo, C. Martín, and V. Rives, "An FT-IR study of the adsorption of isopropanol on calcined layered double hydroxides containing isopolymolybdate," Catalysis Today, vol. 126, no. 1-2, pp. 153-161, 2007. 

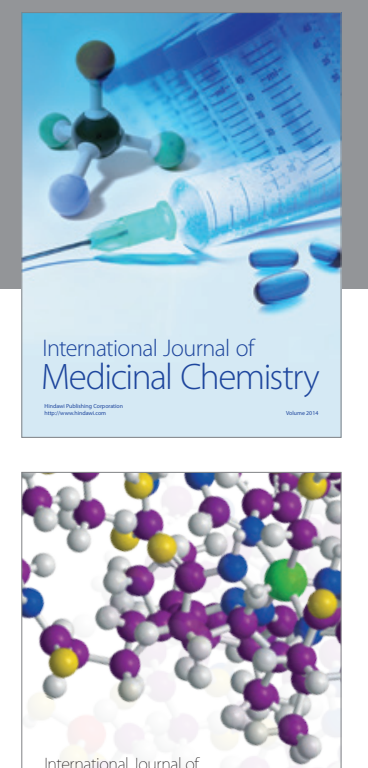

\section{Carbohydrate} Chemistry

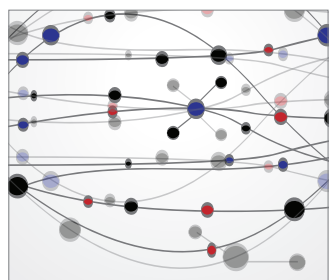

The Scientific World Journal
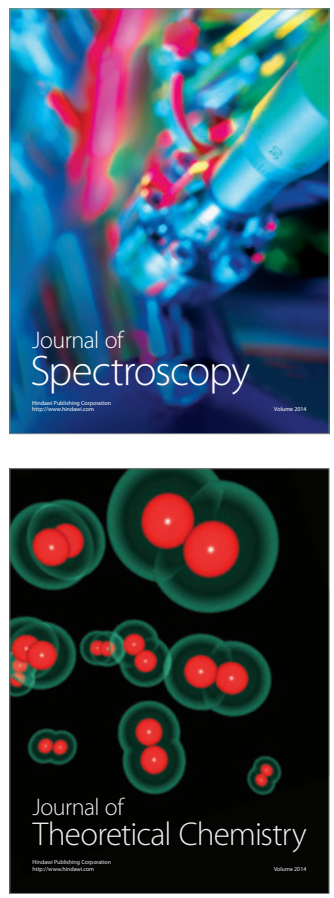
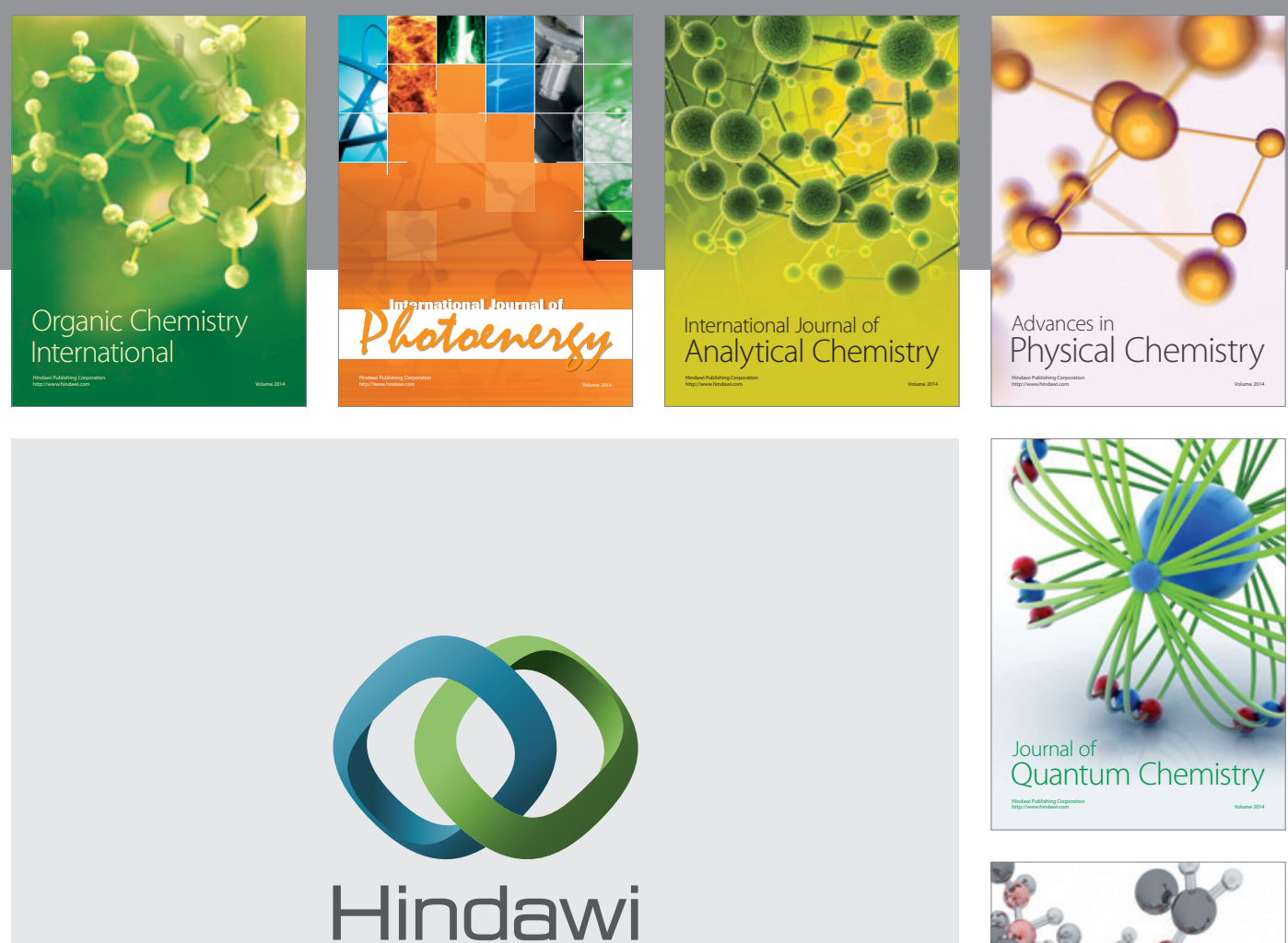

Submit your manuscripts at

http://www.hindawi.com

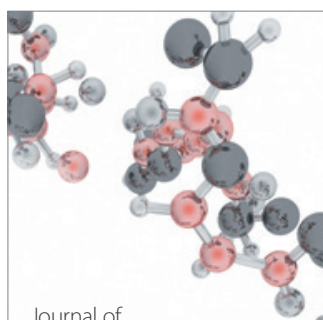

Analytical Methods

in Chemistry

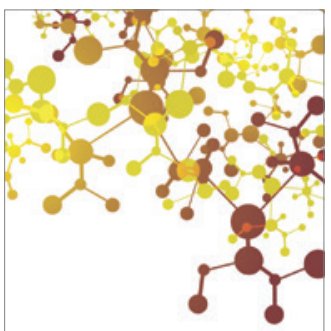

Journal of

Applied Chemistry

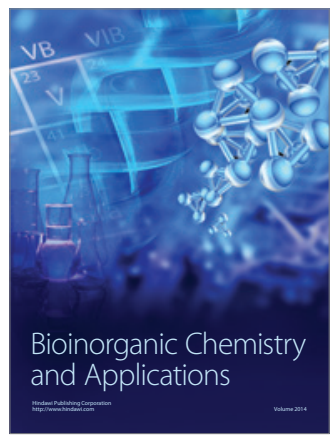

Inorganic Chemistry
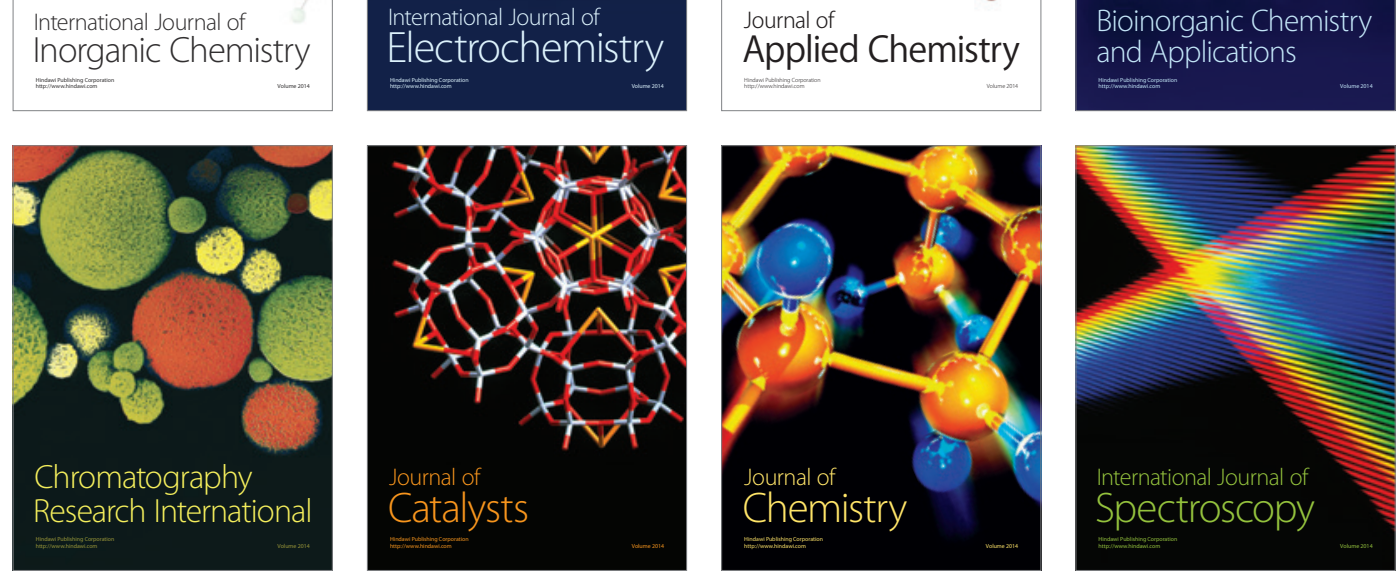